\section{CONJUNTO RESIDENCIAL DE HAMMARBY}

$123-143$

El plan de urbanismo cubre una zona situada en el centro de Norra Hammarbyhamnen contigua a la parte meridional de Katarina Bangata y Malmgärdavägen. La zona cubierta por el plan es de una 15 hectáreas. La zona portuaria y las instalaciones deportivas de Hammarby constituyen el límite al oeste mientras que el canal Hammarby forma el límite al Norte.

El suelo se eleva al oeste y al norte; en algunos puntos, esta elevación es bastante fuerte en el parque de Stora Blecktorn, la zona de Blecktorn y la zona al norte de Färgagärden (el bloque de Malmen).

Las partes centrales de la zona eran antiguamente un lecho de lago que se rellenó con posterioridad. El espesor del relleno es actualmente de unos seis metros. La profundidad al lecho rocoso disminuye rápidamente hacia el oeste y el norte, quedando la roca expuesta en algunos puntos. El nivel de las aguas freáticas en Tegelviksgatan está entre 0 y 1

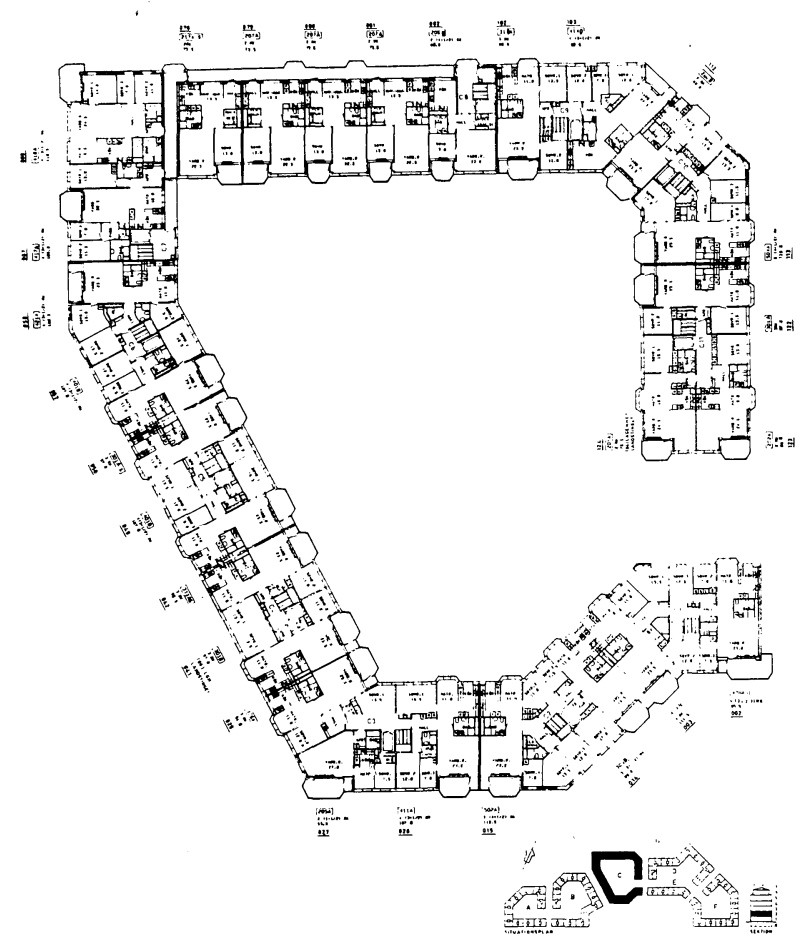

metros por encima del nivel cero y se eleva a la altura de 2 metros en Ljusterögatan.

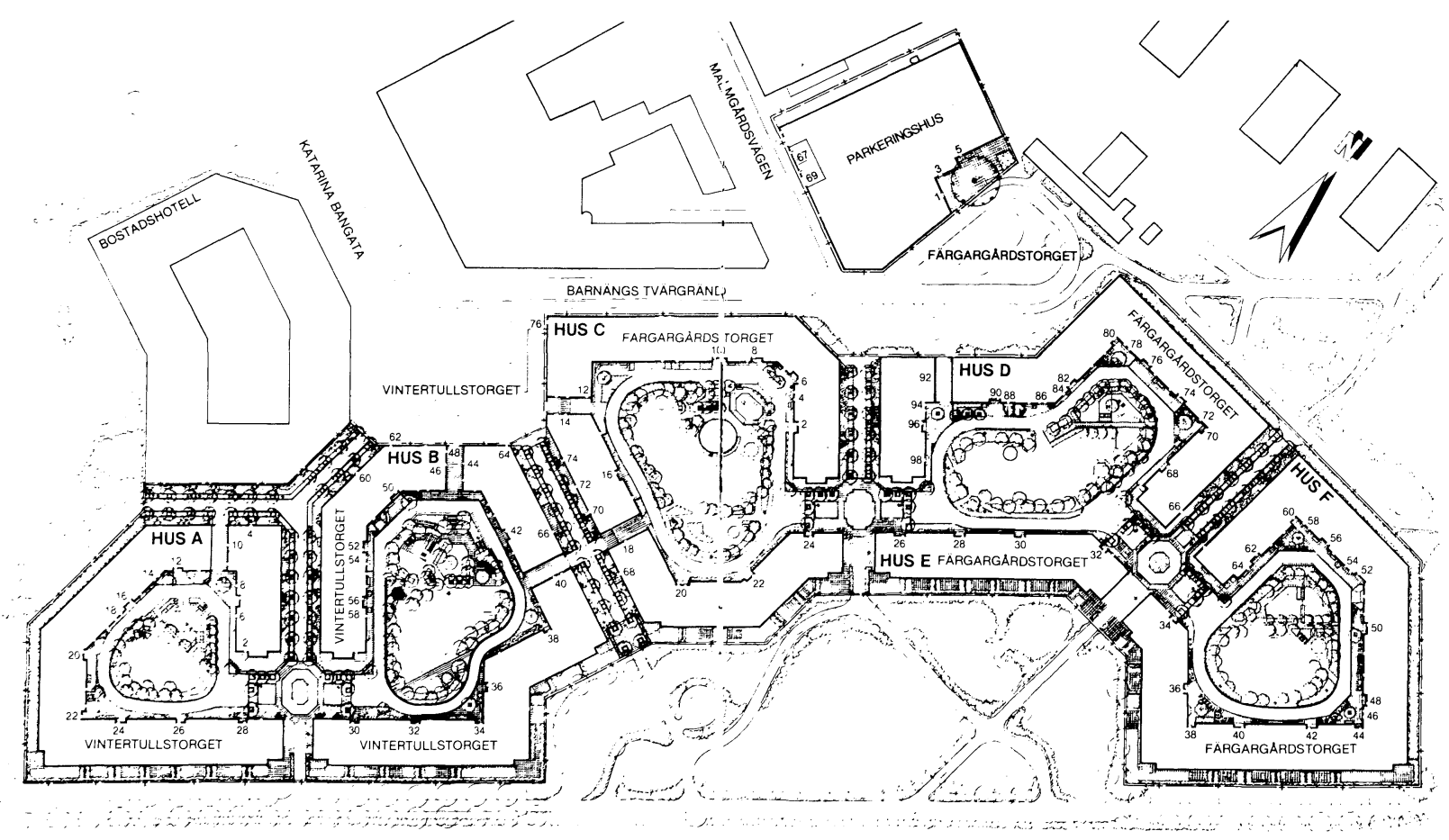




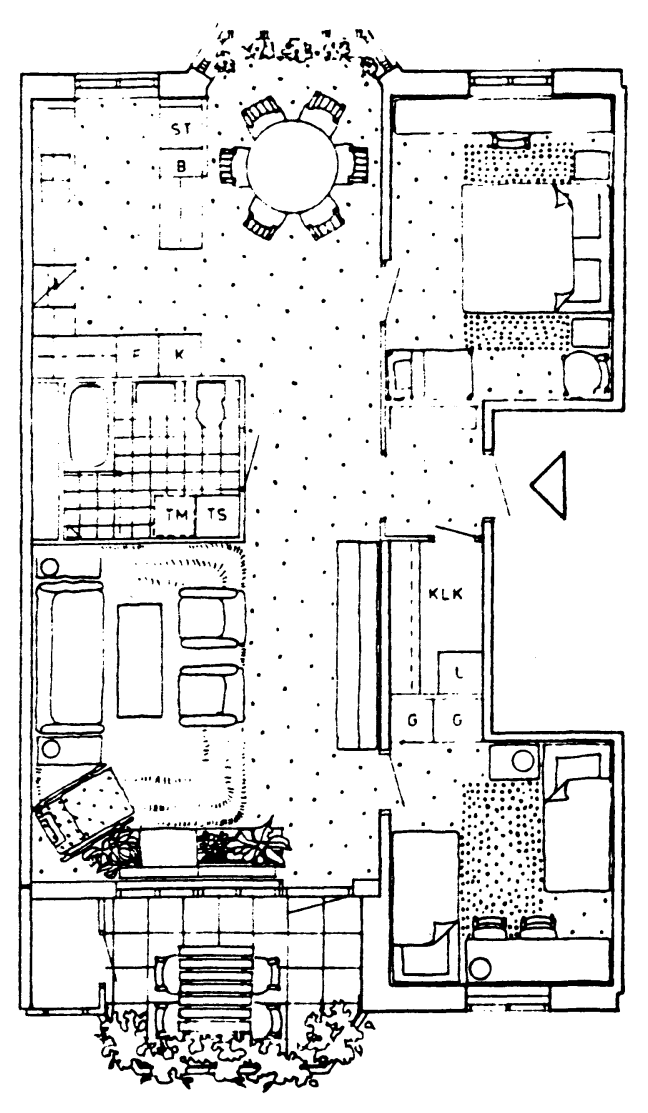

Tres dormitorios $87,50 \mathrm{~m}^{2}$

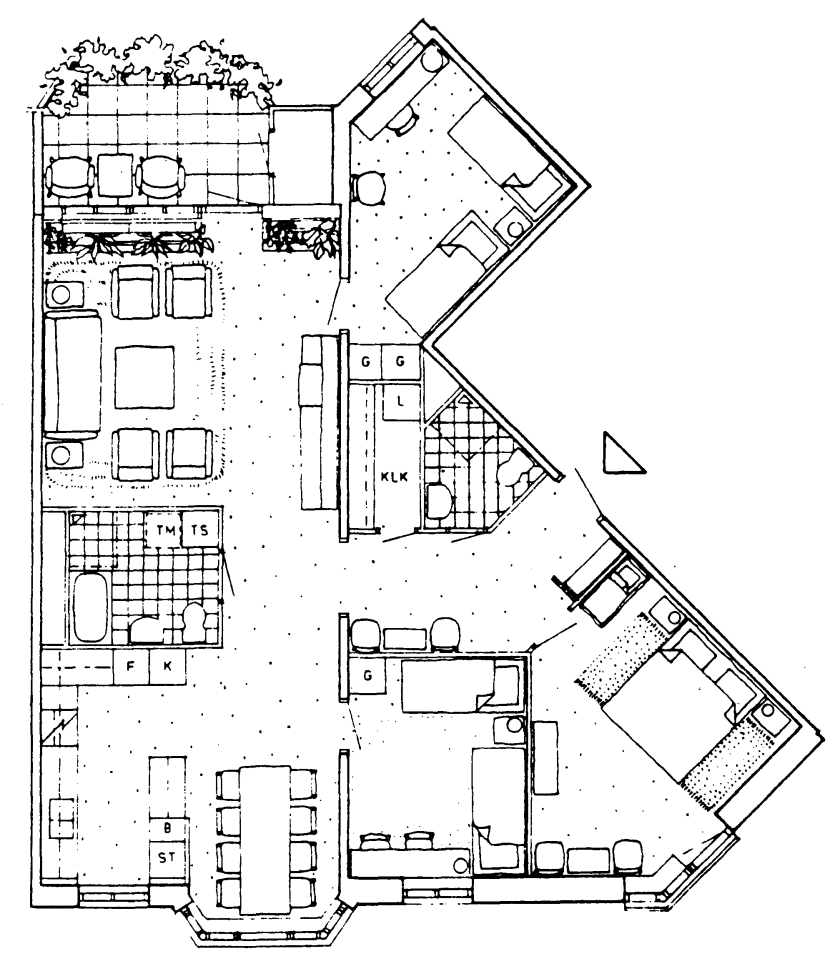

Cuatro dormitorios $111,50 \mathrm{~m}^{2}$

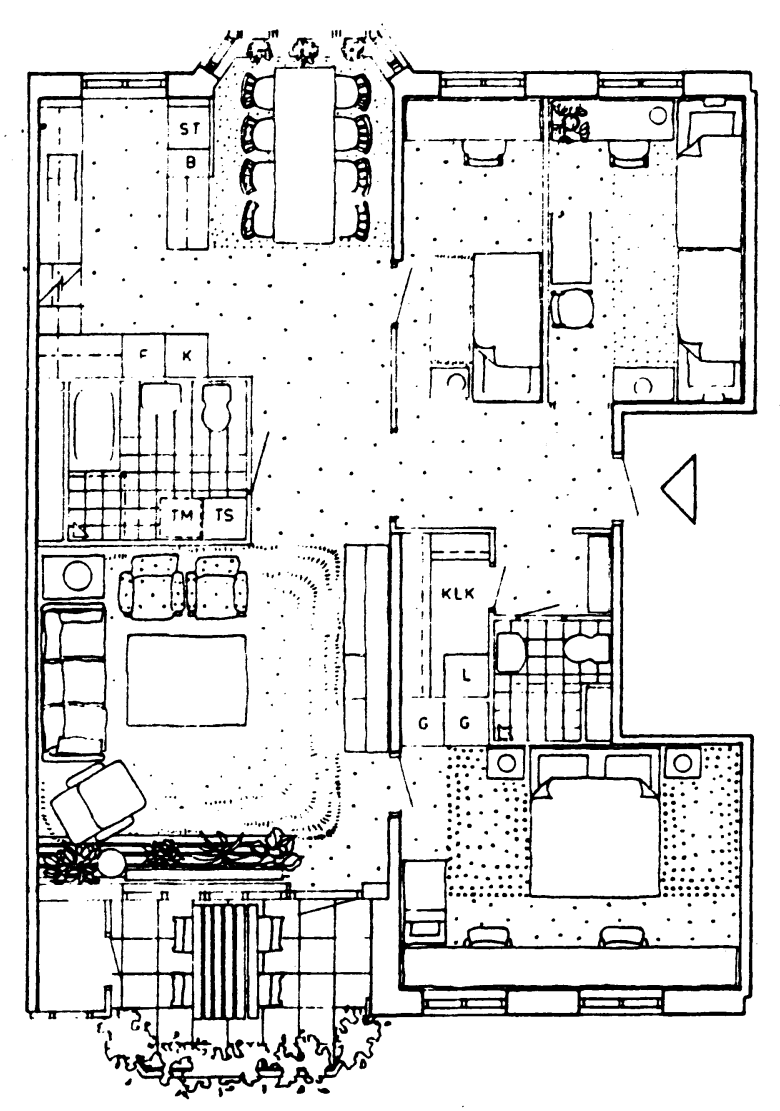

Cuatro dormitorios $107,00 \mathrm{~m}^{2}$

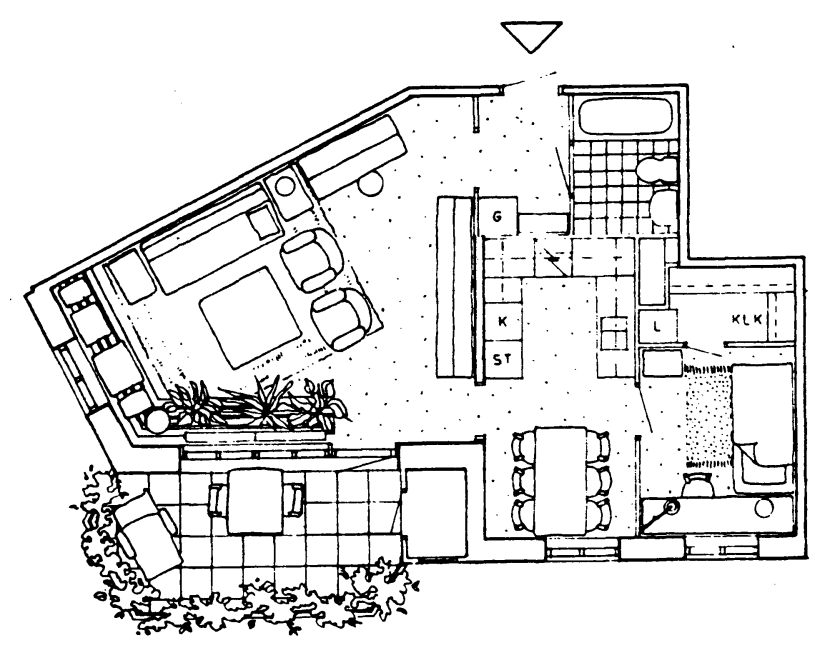

1,5 dormitorios $55,00 \mathrm{~m}^{2}$ 


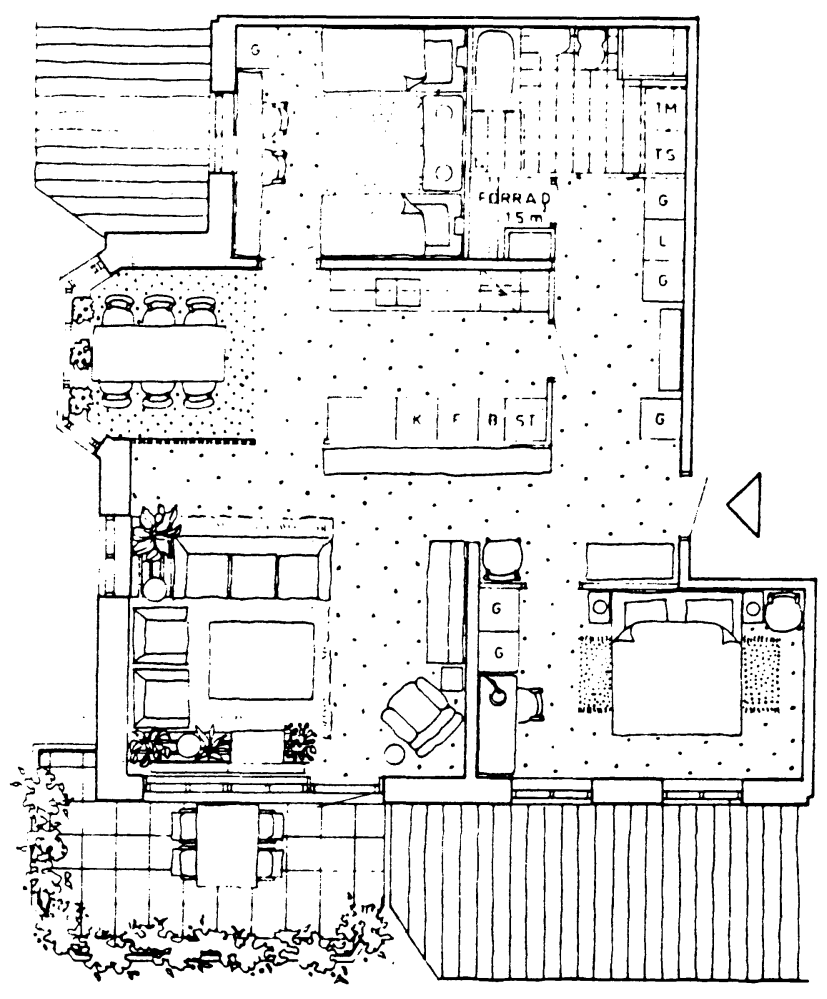

Tres dormitorios $87,5 \mathrm{~m}^{2}$

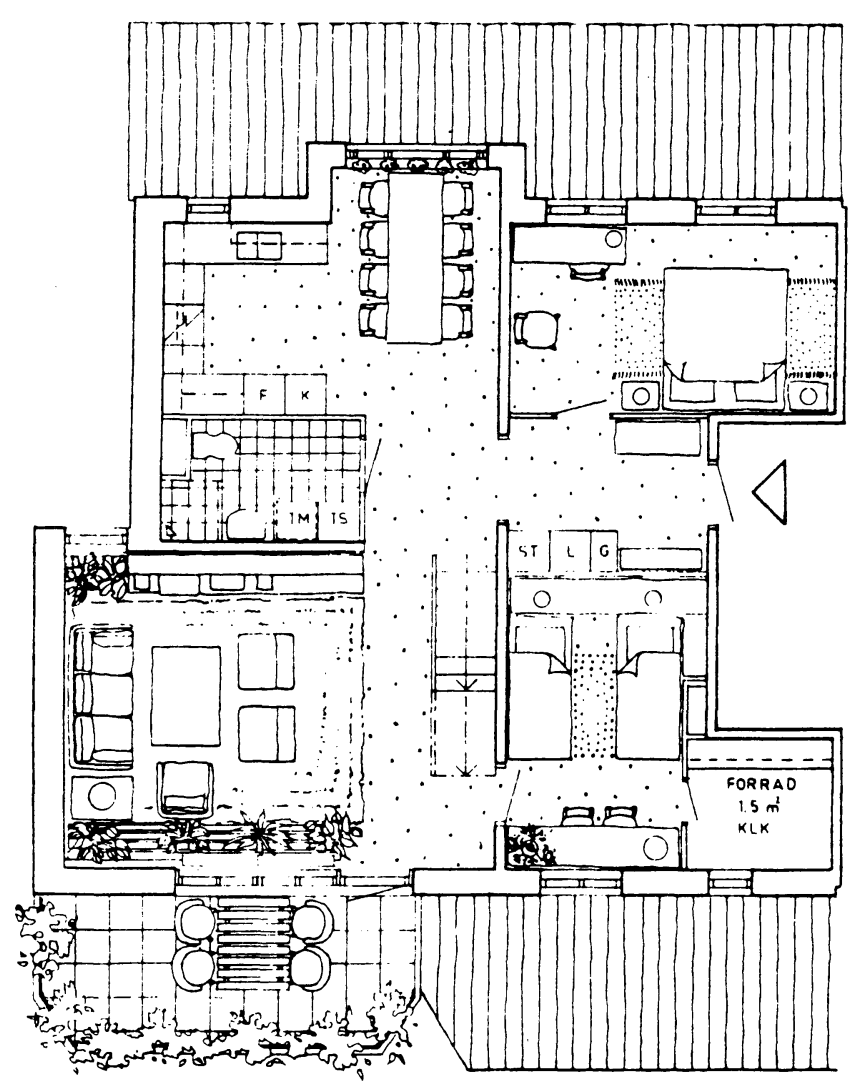

Cinco dormitorios $130,5 \mathrm{~m}^{2}$

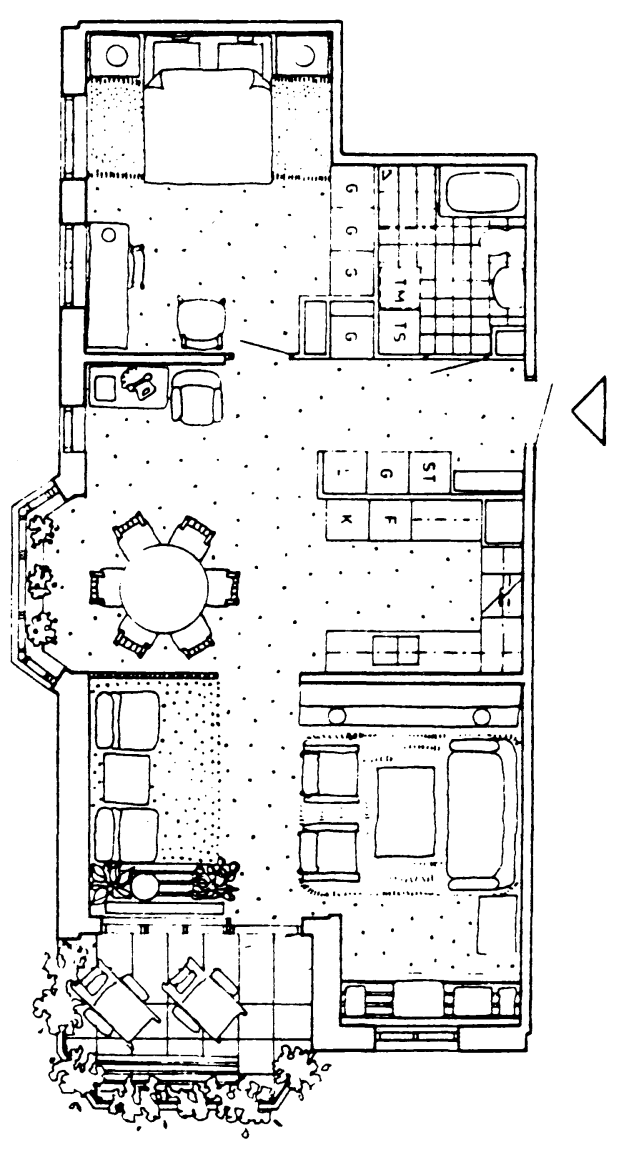

Dos dormitorios $69,00 \mathrm{~m}^{2}$

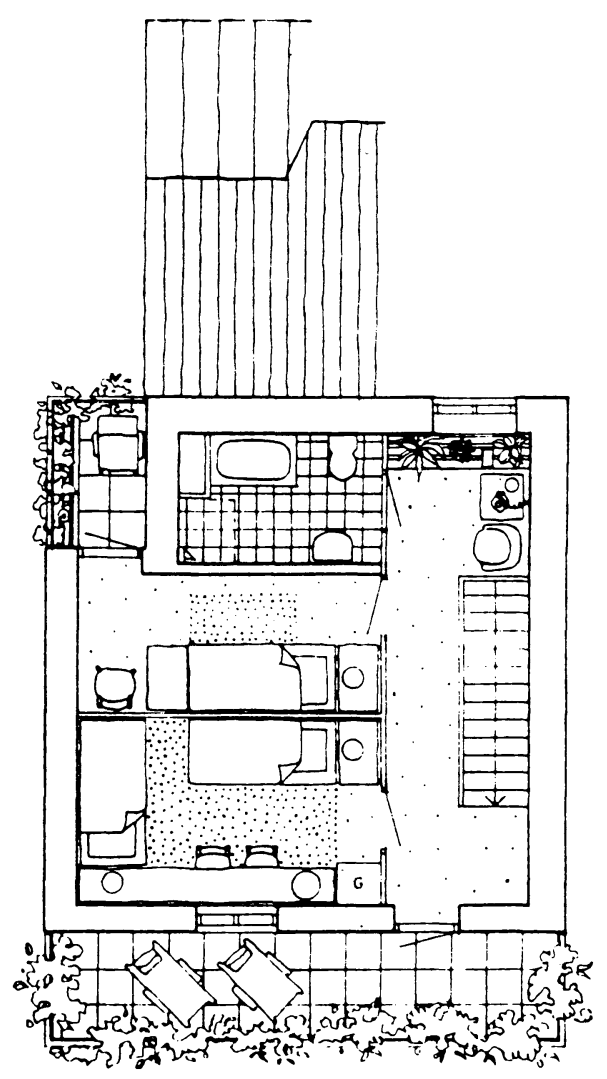




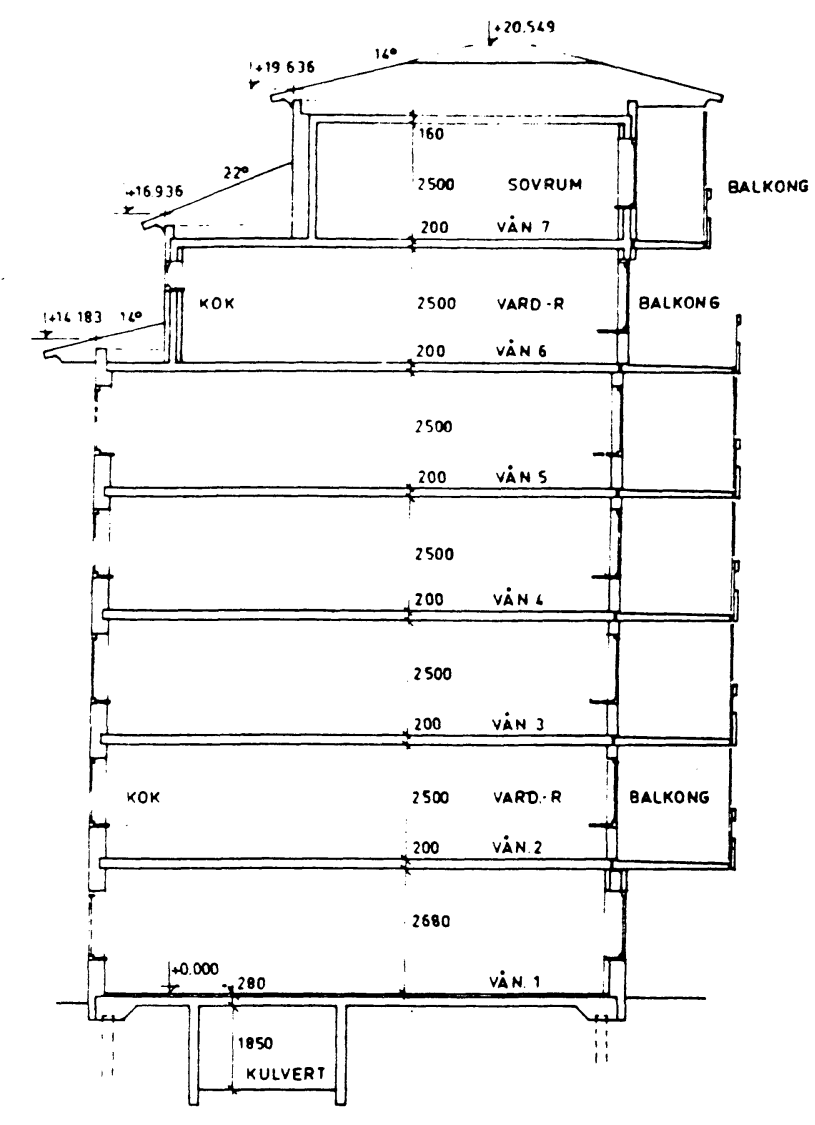

Sección

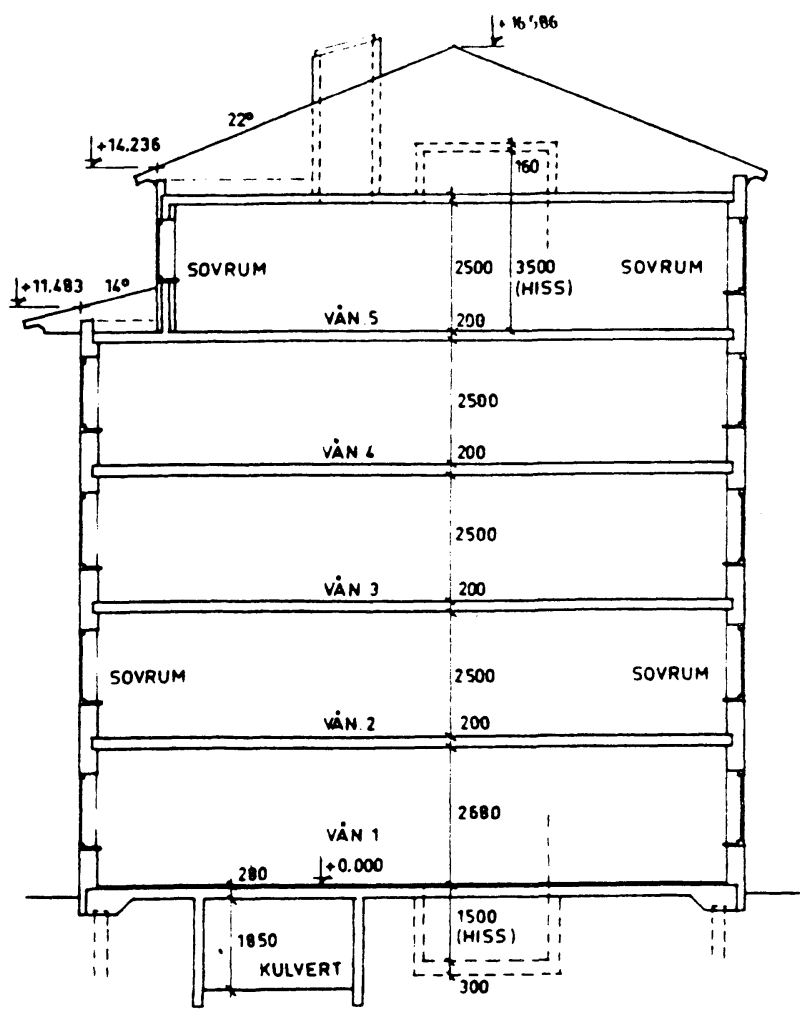

Sección
De acuerdo con el plan de urbanización actualmente en vigor sólo puede construirse un nivel de sótano. Las reglamentaciones del plan de urbanización estipulan también que no pueden utilizarse métodos de construcción que pudieran hacer bajar el nivel de las aguas freáticas durante el período de edificación o con posterioridad.

Los bloques de Barnängen y de Melonen tienen varios edificios de interés histórico. Dichas zonas se han señalado como reserva cultural en el plan de urbanización.

La asociación de arrendatarios, partícipe en la construcción de las viviendas, abarca a 603 viviendas propiedad de los moradores, 30 de las cuales son de establecimientos residenciales. Además, se han construido unas 200 viviendas en la zona, en un conjunto residencial para pensionistas de edad avanzada.

Las viviendas propiedad de los moradores de la asociación y las del conjunto residencial se han concebido como una estructura de vecindad coherente, con zonas verdes para juegos y actividades en exteriores. Los patios están unidos entre sí y a las avenidas, a las plazas y a otras zonas abiertas por medio de portillos y pórticos.

Las alamedas se encuentran abiertas al tráfico de peatones y están pavimentadas con piedra en contraste con el acabado más blando de las zonas verdes. Avenidas de tres vías se incluyen en el proyecto propuesto para reforzar el carácter peatonal de las alamedas.

Las plazas se hallan libres, en principio, de tráfico motorizado, pero vehiculos autorizados pueden tener acceso a las mismas en área de tráfico especialmente marcadas.

Los parques de Stora Blecktorn y de Vitaberg están situados próximos a la zona. La extensión de parque va desde Stora Blecktorn, a lo largo del canal de Hammarby, hasta el patio en Barnängen. Esta extensión se ha ampliado para formar una zona destinada a juegos y actividades recreativas junto al canal y rodeada por el complejo residencial. Los edificios de viviendas tienen cinco pisos y una azotea. Las casas que dan a las avenidas tienen, sin embargo, cuatro pisos con una azotea.

Los edificios se han proyectado con pequeñas torretas que se elevan en un piso por encima de las azoteas, para proporcionar una estructura arquitectónica para el parque en el canal y para destacar las alamedas.

Asimismo, los edificios se han concebido para estar en armonía con los edificios más antiguos en la zona de Blecktorn. Las paredes exteriores se han revestido de yeso tintado en colores suaves, como el amarillo, rosa y pardo claro. 

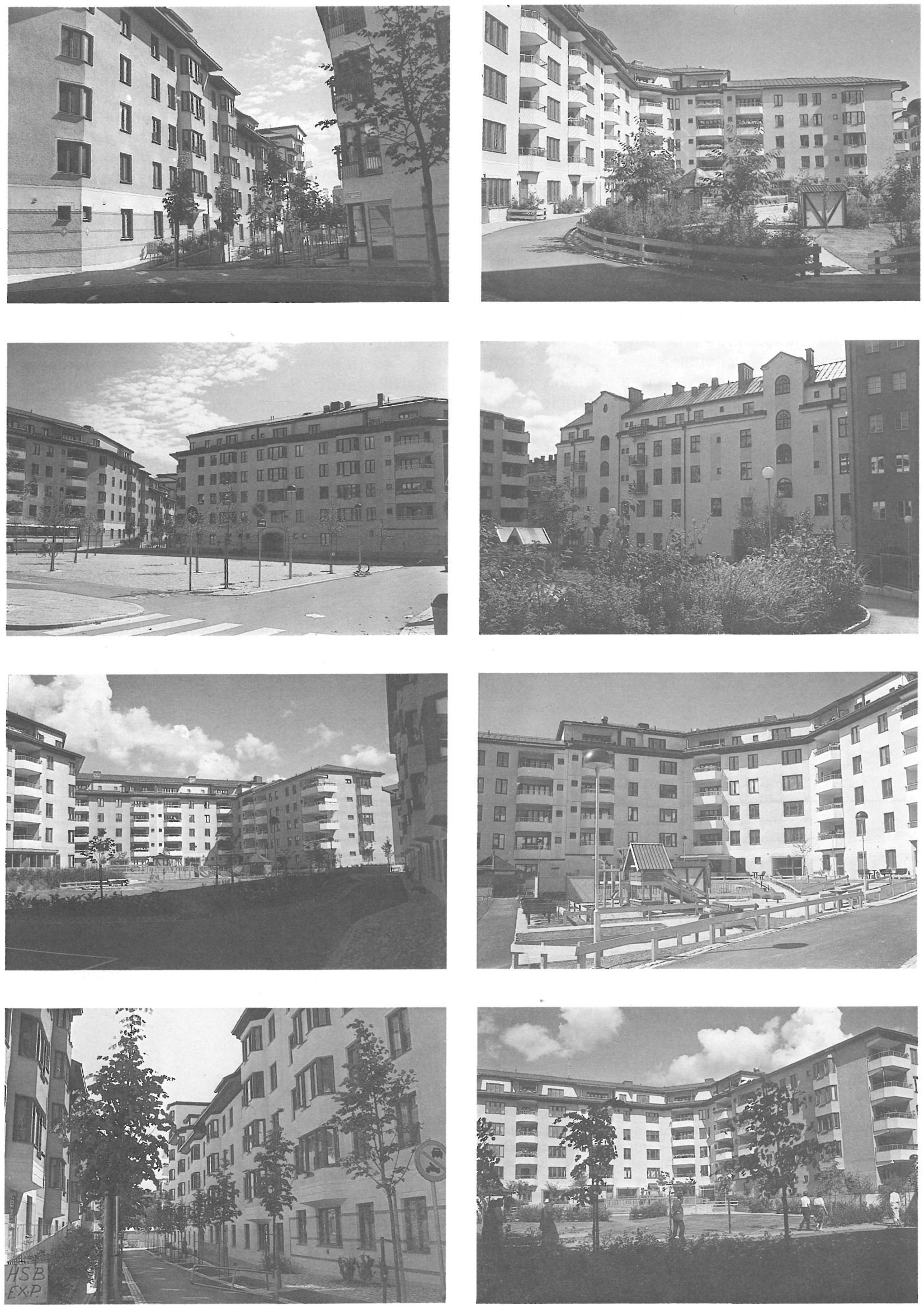


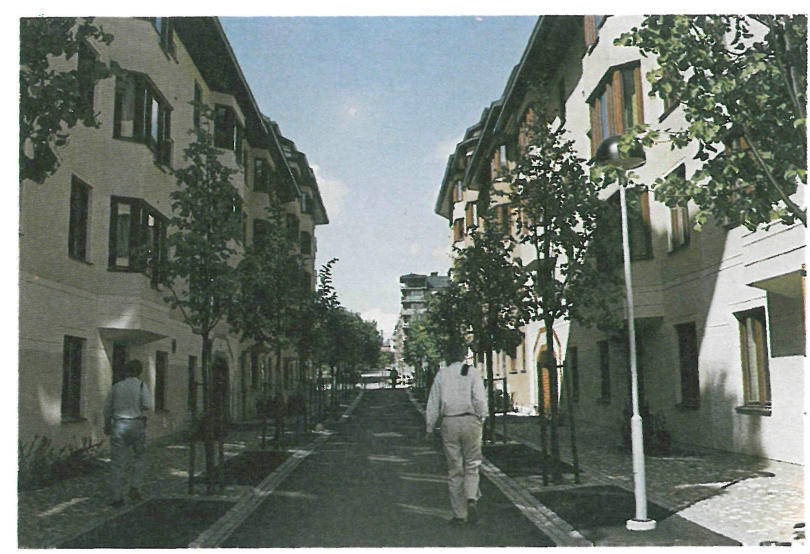

Como se ha mencionado anteriormente, el conjunto residencial para pensionistas se incluye como parte de la estructura de vecindad y se ha concebido para estar en armonía con los edificios de la asociación.
El conjunto residencial incluye un centro sanitario y una guardería para el Consejo del Condado, asi como instalaciones para la oficina de seguros sociales locales.

Los edificios en los bloques de Melonen y de Barnängen serán objeto de renovación y se espera que sean utilizados por las asociaciones y sociedades, así como para actividades de asistencia social del Consejo del Condado.

Se dispone de instalaciones de aparcamiento de coches en una edificación de varios pisos en el bloque de Pumpan.

Las basuras se tratarán en la zona por medio de un sistema de vacío. El terminal colector está situado en la parte occidental de la zona contigua a Tegelviksgatan. Se ha concebido de modo que pueda prestar servicio también a algunos de los edificios más antiguos.

\section{publicación del i.e.t.c.c.}

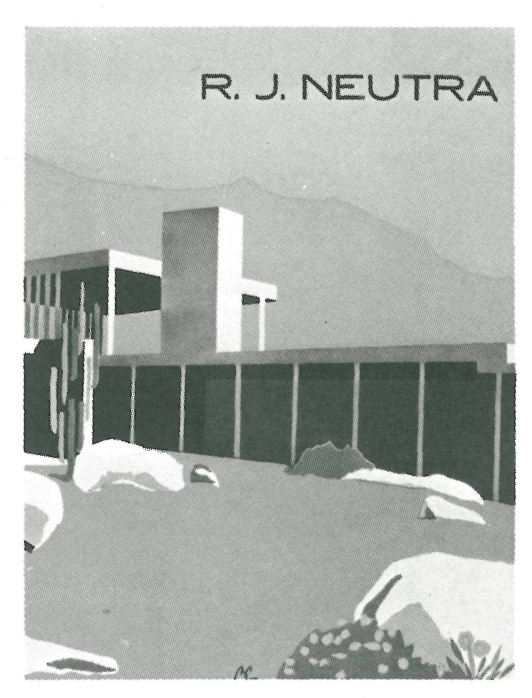

Las viviendas humanas - desde las más modestas hasta las mejor equipadas - han servido de base a los progresivos métodos de investigación clínica, con los que Mr. J. Neutra ha pretendido descubrir la intimidad más recóndita de la vida humana. Los temas preferidos en sus estudios han sido las residencias infantiles, los jardines de la infancia, los sanatorios para niños, los centros de recreo juvenil y, en general, todas las variantes de los centros docentes. Siempre aplicó las formas a condiciones muy especificamente humanas, y siguió con apasionada atención los resultados que las distintas percepciones sensoriales motivaban en el sistema nervioso y endocrino de los hombres, de las mujeres y de los niños. Para Mr. Neutra, lo que cuenta, a la hora de la verdad, es el reflejo humano.

Un volumen encuadernado on tola de $21 \times 27,5 \mathrm{~cm}$, compuesto de 231 páginas y 217 fotos, dibujos y fliguras de línea.

Preclos: España 2.000 ptas. Extranjero $\$ 29.00$. 